\title{
What Are the Biomechanical Effects of Half-pin and Fine-wire Configurations on Fracture Site Movement in Circular Frames?
}

\author{
Daniel J. Henderson FRCS (Orth), Jeremy L. Rushbrook FRCS (Orth), Todd D. Stewart PhD, \\ Paul J. Harwood FRCS (Orth)
}

Received: 3 August 2015/ Accepted: 23 November 2015/Published online: 7 December 2015

(C) The Association of Bone and Joint Surgeons(B) 2015

\begin{abstract}
Background Fine-wire circular frame (Ilizarov) fixators are hypothesized to generate favorable biomechanical conditions for fracture healing, allowing axial micromotion while limiting interfragmentary shear. Use of half-pins increases fixation options and may improve patient comfort by reducing muscle irritation, but they are thought to induce interfragmentary shear, converting beam-to-cantilever loading. Little evidence exists regarding the magnitude and type of strain in such constructs during weightbearing.

Questions/purposes This biomechanical study was designed to investigate the levels of interfragmentary strain

Each author certifies that he or she, or a member of his or her immediate family, has no funding or commercial associations (eg, consultancies, stock ownership, equity interest, patent/licensing arrangements, etc) that might pose a conflict of interest in connection with the submitted article.

All ICMJE Conflict of Interest Forms for authors and Clinical Orthopaedics and Related Research ${ }^{\mathbb{R}}$ editors and board members are on file with the publication and can be viewed on request. Clinical Orthopaedics and Related Research ${ }^{\mathbb{R}}$ neither advocates nor endorses the use of any treatment, drug, or device. Readers are encouraged to always seek additional information, including FDAapproval status, of any drug or device prior to clinical use. This work was performed in the laboratories of the Institute of Medical and Biological Engineering at the University of Leeds, Leeds, UK.
\end{abstract}

D. J. Henderson ( $₫)$, J. L. Rushbrook, P. J. Harwood Department of Orthopaedics, Leeds General Infirmary, Great George Street, Leeds LS1 3EX, UK

e-mail: Daniel.Henderson@nhs.net;

danhenderson50@hotmail.com

D. J. Henderson, J. L. Rushbrook, T. D. Stewart Institute of Medical and Biological Engineering, School of Mechanical Engineering, University of Leeds, Leeds, UK occurring during physiologic loading of an Ilizarov frame and the effect on this of substituting half-pins for finewires.

Methods The "control" construct was comprised of a four-ring all fine-wire construct with plain wires at $90^{\circ}$ crossing angles in an entirely unstable acrylic pipe synthetic fracture model. Various configurations, substituting half-pins for wires, were tested under levels of axial compression, cantilever bending, and rotational torque simulating loading during gait. In total three frames were tested for each of five constructs, from all fine-wire to all half-pin.

Results Substitution of half-pins for wires was associated with increased overall construct rigidity and reduced planar interfragmentary motion, most markedly between all-wire and all-pin frames (axial: $5.9 \mathrm{~mm} \pm 0.7 \mathrm{vs} 4.2 \mathrm{~mm} \pm 0.1$, mean difference, $1.7 \mathrm{~mm}, 95 \% \mathrm{CI}, 0.8-2.6 \mathrm{~mm}, \mathrm{p}<0.001$; torsional: $1.4 \% \pm 0.1$ vs $1.1 \% \pm 0.0$ rotational shear, mean difference, $0.3 \%, 95 \% \mathrm{CI}, 0.1 \%-0.5 \%, \mathrm{p}=0.011$; bending: $7.5^{\circ} \pm 0.1$ vs $3.4^{\circ} \pm 0.1$, mean difference, $-4.1^{\circ}, 95 \% \mathrm{CI}$, $-4.4^{\circ}$ to $\left.-3.8^{\circ}, \mathrm{p}<0.001\right)$. Although greater transverse shear strain was observed during axial loading $(0.4 \% \pm 0.2$ vs $1.9 \% \pm 0.1$, mean difference, $1.4 \%$, 95\% CI, $1.0 \%-$ $1.9 \%, \mathrm{p}<0.001)$, this increase is unlikely to be of clinical relevance given the current body of evidence showing bone healing under shear strains of up to $25 \%$. The greatest transverse shear was observed under bending loads in all fine-wire frames, approaching 30\% (29\% \pm 1.9$)$. This was reduced to $8 \%( \pm 0.2)$ by incorporation of sagittal plane half-pins and $7 \%( \pm 0.2)$ in all half-pin frames (mean difference, $-13.2 \%$ and $-14.0 \%, 95 \% \mathrm{CI},-16.6 \%$ to $9.7 \%$ and $-17.5 \%$ to $-10.6 \%$, both $\mathrm{p}<0.001$ ).

Conclusions Appropriate use of half-pins may reduce levels of shear strain on physiologic loading of circular frames without otherwise altering the fracture site 
mechanical environment at levels likely to be clinically important. Given the limitations of a biomechanical study using a symmetric and uniform synthetic bone model, further clinical studies are needed to confirm these conclusions in vivo.

Clinical Relevance The findings of this study add to the overall understanding of the mechanics of circular frame fixation and, if replicated in the clinical setting, may be applied to the preoperative planning of frame treatment, particularly in unstable fractures or bone transport where control of shear strain is a priority.

\section{Introduction}

The Ilizarov method is clinically established in fracture management, limb salvage, and deformity correction [10, 18]. Research has been conducted to determine the basic mechanisms underlying this technique and is particularly relevant as insights are gained in the biomechanical requirements for and biology of bone healing. The mechanical environment at a fracture or osteotomy site is a principal factor in achieving union with certain levels of mechanical stimulus required to initiate and propagate secondary bone healing [14]. It generally is accepted that certain levels of axial motion help stimulate healing, whereas shear may delay or prevent it, potentially resulting in nonunion. Studies of this subject, however, while confirming the beneficial effects of axial micromotion, often fail to agree on the detrimental effect of shear strain, with Bishop et al. [2] reporting improved fracture healing with $25 \%$ shear strain over rigid fixation, and the topic clearly is not yet fully understood [8, 16]. The Ilizarov method, through variation of construct and fixation elements, allows powerful manipulation of fracture site mechanics, and it generally is considered that correct application of fine-wire circular frame fixation methods can help control the mechanical environment at a fracture site in ways conducive to bone healing [5, 9]. Crossed, tensioned fine-wires appear to generate a self-stiffening, beam-loading environment, producing favorable levels of axial micromotion while limiting shear as patients bear weight [5, 20, 24].

The main disadvantage of fine-wires is the relatively narrow anatomic corridors in which they can be placed to minimize the risk of neurovascular damage [6]. By their nature, these wires often transfix muscle and irritate tendons, leading to pain, loss of mobility, and potentially increasing the risk of pin site infection. Half-pins, by contrast, can be inserted safely through the majority of the tibia in an arc from anterior to direct medial, across the subcutaneous face of the tibia [6]. This opens wider avenues of fixation and largely avoids muscle transfixation. Some surgeons advocate the use of half-pins on the basis that this will increase patient comfort and compliance [4, 13]; however, the introduction of half-pins in a construct potentially leads to cantilever bending during loading, which is theorized to increase shear at the fracture [13]. For this reason some surgeons avoid the use of half-pins wherever possible. Despite these opposing viewpoints, there is little experimental evidence investigating interfragmentary strain that occurs in circular frames using finewires or half-pins and none to our knowledge addressing the complex loading forces placed on the framed limb during gait.

This biomechanical study therefore was designed to investigate the following research questions: (1) What type and magnitude of interfragmentary strain occurs on loading of a simulated tibial fracture in an Ilizarov fine-wire frame under physiologic levels of axial loading, axial torsion, and bending loads? (2) How is interfragmentary strain altered by substitution of half-pins for fine-wires under these conditions? From this we hoped to determine the ideal frame construct for optimizing the mechanical environment under physiologic loading conditions.

\section{Materials and Methods}

An experimental biomechanical study was designed using an acrylic tube with an outer diameter of $32 \mathrm{~mm}$ and a 4mm wall (Clear Plastic Supplies, Chesterfield, UK), as a mechanical substitute for bone. This symmetric, uniform model was selected to minimize variability between testing cycles attributable to minor variations in wire and pin placement in more anatomic models, and to allow focus to be kept on the effect of altering bone fixation elements alone. This methodology is in keeping with previous studies [21-24, 26, 27].

Five construct configurations were sequentially tested: all fine-wire frame; all half-pin frame; fine-wires with one half-pin either side of the fracture in the same plane; one wire and one half-pin at each ring with pins at $90^{\circ}$ on adjacent rings; and one wire and one half-pin at each ring with all half-pins in the same plane (Fig. 1). The all finewire fixation model was tested with bending load in the plane perpendicular to the wires and at $45^{\circ}$.

Three identical four-ring frames were tested for each configuration with $50 \mathrm{~mm}$ between common segment rings and $175 \mathrm{~mm}$ across the interfragmentary segment, constructed according to the manufacturer's specifications, using $155-\mathrm{mm}$ aluminum Taylor Spatial Frame ${ }^{\mathrm{TM}}$ rings (Smith \& Nephew, Inc, Memphis, TN, USA) with four 6$\mathrm{mm}$ threaded rods between each ring.

The plastic simulated bone segments were mounted with a 20-mm simulated fracture gap to prevent cylinder end apposition during loading, mimicking an entirely 
Fig. 1 The five frame configurations tested, wires only, wires and pins construct 1 , wires and pins construct 2, wires and pins construct 3 , and pins only, are shown.

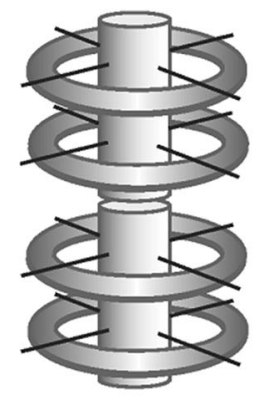

Wires Only

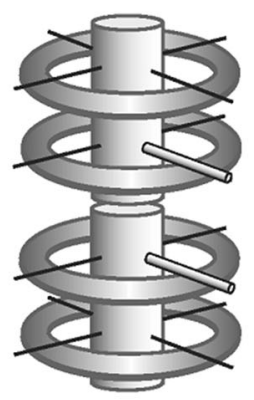

Wires/Pins 1

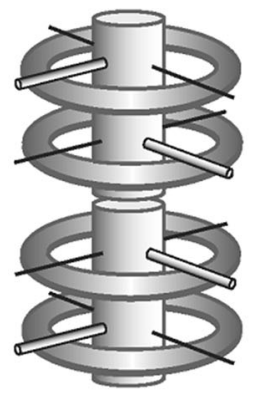

Wires/Pins 2

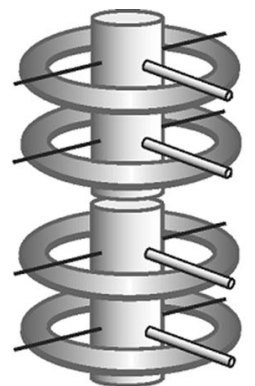

Wires/Pins 3

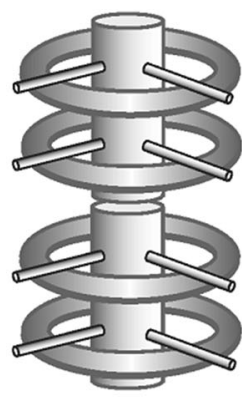

Pins Only unstable fracture or corticotomy. Fixation was achieved using previously unused clinical standard $1.8-\mathrm{mm}$ smooth wires, tensioned to $130 \mathrm{~kg}$, or predrilled 5-mm self-tapping half-pins. To maximize reproducibility of the study, to isolate the effect of half-pin use, and in keeping with previous studies, wires and pins were placed at theoretically "ideal" crossing angles of $90^{\circ}$ with the bone substitute mounted centrally in each ring [5, 23, 27]. Plain wires were used throughout.

Constructs were mounted in the testing apparatus (Tinius Olsen H25K-S UTM; Tinius Olsen Inc, Horsham, PA, USA; uniaxial manual torsion testing machine; University of Leeds, Leeds, UK) using bespoke mounting jigs, allowing rigid fixation of each end of the bone substitute to the apparatus (Fig. 2).

Each frame was tested separately in axial loading, AP cantilever bending, and axial torsion. Three preconditioning cycles of full loading were applied before data collection at loading rates of $6 \mathrm{~mm} /$ minute $/ 1.01 \%$ minute. Loading was applied to a maximum of $700 \mathrm{~N}$ axially, 20 $\mathrm{Nm}$ bending, and $20 \mathrm{Nm}$ torsion. A previous study [7] showed that by 30 days postoperatively the majority of patients with tibial circular fixation are placing full body weight through their affected limb, and a clinical study [28], using instrumented frames, showed that in severely comminuted fractures up to $70 \%$ of ground reaction force is supported by the frame as axial load, $2.5 \%(\mathrm{Nm} / \mathrm{N})$ as bending load, and $0.75 \%(\mathrm{Nm} / \mathrm{N})$ as torsion. On the basis of an $80-\mathrm{kg}$ patient therefore, physiologic loading was considered to consist of 500-N axial loading, 20-Nm bending, and $6-\mathrm{Nm}$ torsional load, rounded to $5-\mathrm{Nm}$ for testing.

Strain was recorded through measurement of bone segment displacement during loading using Digimatic linear variable differential transformers, with $0.01 \mathrm{~mm}$ resolution (Mitutoyo UK Ltd, Andover, UK), positioned at the fracture site to record interfragmentary movement in three planes (Fig. 3).

Data were collected, collated, and tabulated using Microsoft Excel ${ }^{\circledR}$ (Microsoft Corporation, Redmond, WA, USA), with data sets subsequently transferred for graph

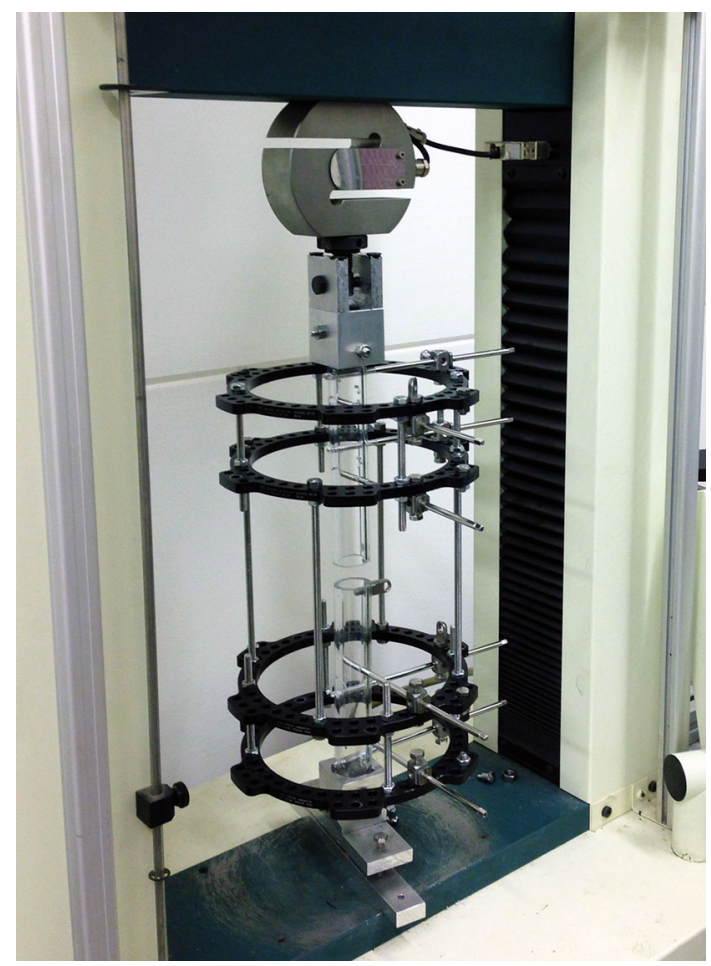

Fig. 2 An all half-pin frame mounted in the axial testing apparatus (Tinius Olsen H25K-S UTM; Tinius Olsen Inc, Horsham, PA, USA) is shown.

plotting and statistical analysis to Graph Pad Prism ${ }^{\circledR}$ (Version 6; GraphPad Software, Inc, La Jolla, CA, USA). Load deformation curves were created for each construct and loading regime for the full range of loading. Maximum interfragmentary displacement at physiologic loading then was determined. Displacement in the plane of applied load ( $\mathrm{mm}$, degrees bending, or degrees rotation) was plotted against composite transverse plane shear strain (mm and \% strain). Statistical analysis was done to determine whether there was any significant difference in interfragmentary movement between the tested constructs. The data met the assumptions for parametric testing using the D'AgostinoPearson omnibus test and QQ-plot analysis and therefore ANOVA testing for statistical significance was done with 


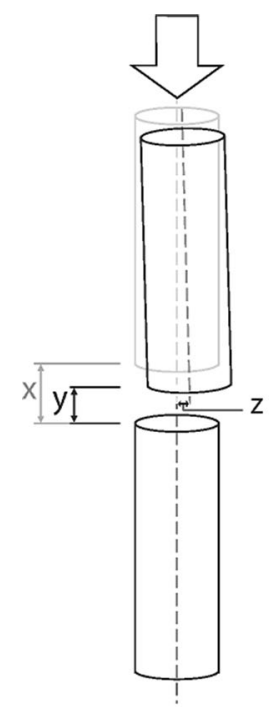

A

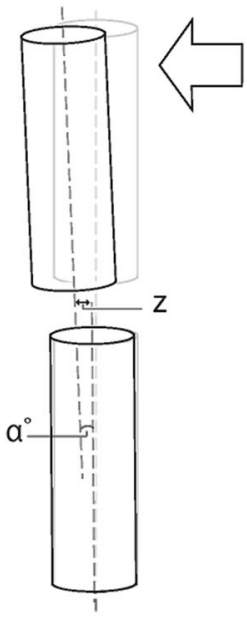

B
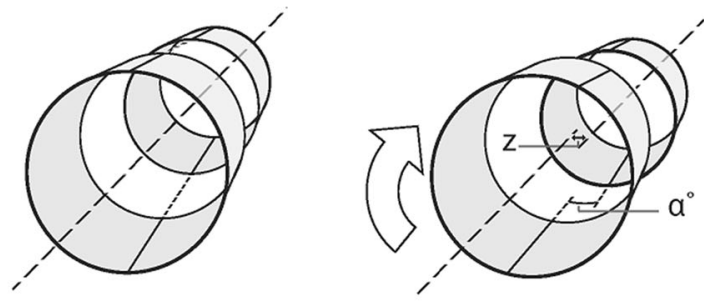

C

Fig. 3A-C The planes of displacement, $(\mathbf{A})$ axial loading (axial displacement $=\mathrm{x}-\mathrm{y}$, linear transverse shear $=\mathrm{z}$ ), (B) bending loading $($ angular deformation $=\alpha$, linear transverse shear $=\mathrm{z}$ ) and $(\mathbf{C})$ torsional loading (rotational deformation $=\alpha$, linear transverse shear $=\mathrm{z}$ ) are shown.

post hoc analysis using Tukey's method. A probability value less than 0.05 was considered statistically significant throughout.

\section{Results}

\section{Axial Loading}

Under axial loading the all fine-wire construct underwent nonlinear axial deformation as load increased. At 500-N loading, a mean axial interfragmentary motion of $5.9 \mathrm{~mm}$ compression was observed with minimal transverse linear shear of $0.4 \%$ (Fig. 4). By contrast, the all half-pin construct was more rigid and performed more consistently with lower mean interfragmentary compression of $4.2 \mathrm{~mm}$ (mean difference, $1.7 \mathrm{~mm}, 95 \% \mathrm{CI}, 0.8-2.6 \mathrm{~mm}, \mathrm{p}<$ 0.001 ) but greater transverse shear strain of $1.9 \%$ (mean difference, 1.4\%, 95\% CI, 1.0\%-1.9\%, p < 0.001) (Fig. 4). The hybrid pin and wire constructs showed axial interfragmentary motion that was not different from those of the wire frames at $5.9 \mathrm{~mm}, 5.3 \mathrm{~mm}$, and $5.2 \mathrm{~mm}$ for constructs 1,2 , and 3, respectively (mean differences, $-0.1 \mathrm{~mm}, 0.6$ $\mathrm{mm}, 0.7 \mathrm{~mm}, 95 \% \mathrm{CI},-1.0$ to $0.7 \mathrm{~mm},-0.3$ to $1.5 \mathrm{~mm}$, -0.2 to $1.6 \mathrm{~mm}, \mathrm{p}=0.983, \mathrm{p}=0.239$, and $\mathrm{p}=0.147$ ). However, the hybrid constructs showed greater shear strains: $1.4 \%, 1.0 \%$, and $2.0 \%$, respectively, compared with the wire frame (mean differences, $1.0 \%, 0.6 \%, 1.6 \%, 95 \%$ CI, $0.5 \%-1.4 \%, 0.1 \%-1.1 \%, 1.1 \%-2.1 \%, \mathrm{p}<0.001, \mathrm{p}=$ 0.010 , and $\mathrm{p}<0.001$ ) (Table 1).

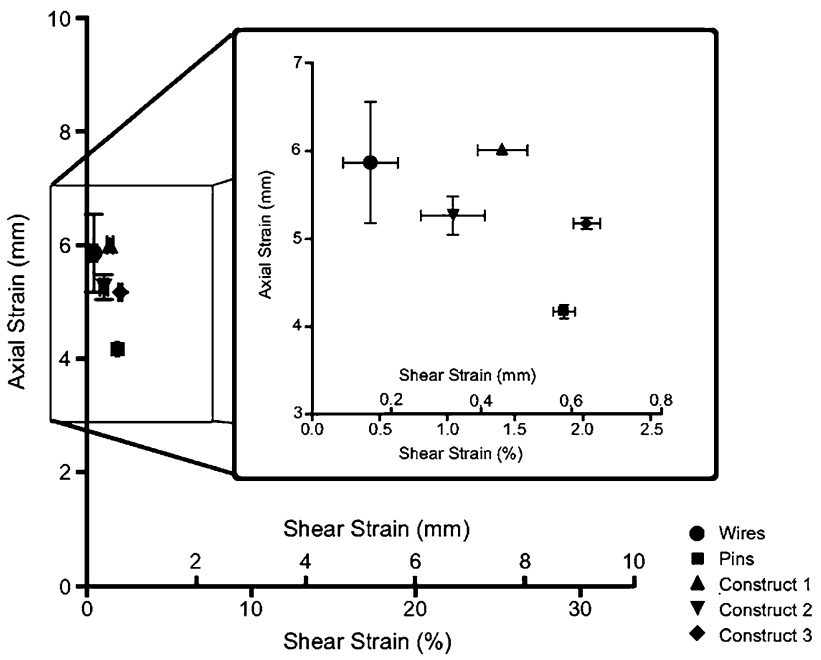

Fig. 4 The maximum axial and shear strains observed under 500-N axial loading are shown.

\section{Axial Torsion}

Under torsional loading of $5 \mathrm{Nm}$, a mean interfragmentary rotational shear strain of $1.4 \%$ was observed in the wire frame with negligible transverse shear (Fig. 5). The all half-pin frames were more rigid, producing only $1.1 \%$ rotational shear strain at $5 \mathrm{Nm}$ (mean difference, $0.3 \mathrm{Nm}$, 95\% CI, $0.1-0.5 \mathrm{Nm}, \mathrm{p}=0.011$ ) but with no difference observed in lateral translation at the fracture site, at $0.4 \%$ (mean difference, $0.4 \%, 95 \% \mathrm{CI},-0.9 \%$ to $1.6 \%, \mathrm{p}=$ 0.851 ). Hybrid construct 3 , with one half-pin and one wire on each ring, also showed increased rigidity compared with 
Table 1. Results table for construct testing under axial, torsional, and bending loads

\begin{tabular}{|c|c|c|c|c|c|c|}
\hline Mode of loading & Fracture site movement & All wires & All half-pins & Construct 1 & Construct 2 & Construct 3 \\
\hline \multirow[t]{3}{*}{ Axial loading $500 \mathrm{~N}$} & Axial displacement (mm) & $5.9 \pm 0.7$ & $4.2 \pm 0.1$ & $6.0 \pm 0.0$ & $5.3 \pm 0.2$ & $5.2 \pm 0.1$ \\
\hline & Translational shear (mm) & $0.1 \pm 0.1$ & $0.6 \pm 0.0$ & $0.4 \pm 0.1$ & $0.3 \pm 0.1$ & $0.6 \pm 0.0$ \\
\hline & Translational shear strain & $0.4 \% \pm 0.2 \%$ & $1.9 \% \pm 0.1 \%$ & $1.4 \% \pm 0.2 \%$ & $1.0 \% \pm 0.2 \%$ & $2.0 \% \pm 0.1 \%$ \\
\hline \multirow[t]{3}{*}{ Torsional loading $5 \mathrm{Nm}$} & Torsional shear strain & $1.4 \% \pm 0.1 \%$ & $1.1 \% \pm 0.0 \%$ & $1.6 \% \pm 0.1 \%$ & $1.2 \% \pm 0.1 \%$ & $1.1 \% \pm 0.1 \%$ \\
\hline & Translational shear (mm) & $0.0 \pm 0.0$ & $0.1 \pm 0.1$ & $1.0 \pm 0.1$ & $0.1 \pm 0.0$ & $0.5 \pm 0.3$ \\
\hline & Translational shear strain & $0.0 \% \pm 0.0 \%$ & $0.4 \% \pm 0.2 \%$ & $3.2 \% \pm 0.4 \%$ & $0.2 \% \pm 0.1 \%$ & $1.8 \% \pm 0.9 \%$ \\
\hline Bending loading $20 \mathrm{Nm}$ & Bending displacement $\left({ }^{\circ}\right)$ & $7.5 \pm 0.1$ & $3.4 \pm 0.1$ & $6.2 \pm 0.2$ & $5.6 \pm 0.1$ & $3.2 \pm 0.0$ \\
\hline \multirow[t]{2}{*}{ Hybrid pins in sagittal plane } & Translational shear (mm) & $6.4 \pm 0.7$ & $2.2 \pm 0.1$ & $4.8 \pm 0.5$ & $4.0 \pm 0.1$ & $2.5 \pm 0.1$ \\
\hline & Translational shear strain & $21 \% \pm 2.2 \%$ & $7 \% \pm 0.2 \%$ & $16 \% \pm 1.5 \%$ & $13 \% \pm 0.4 \%$ & $8 \% \pm 0.2 \%$ \\
\hline \multirow[t]{3}{*}{ Wires $45^{\circ}$ and hybrid pins coronal } & Bending displacement $\left({ }^{\circ}\right)$ & $8.5 \pm 0.1$ & & $4.6 \pm 0.1$ & $5.1 \pm 0.1$ & $4.6 \pm 0.0$ \\
\hline & Translational shear (mm) & $8.8 \pm 0.6$ & & $6.1 \pm 0.3$ & $6.0 \pm 0.3$ & $4.7 \pm 0.0$ \\
\hline & Translational shear strain & $29 \% \pm 1.9 \%$ & & $20 \% \pm 1.1 \%$ & $19 \% \pm 0.9 \%$ & $15 \% \pm 0.1 \%$ \\
\hline
\end{tabular}

Values are mean \pm SD.

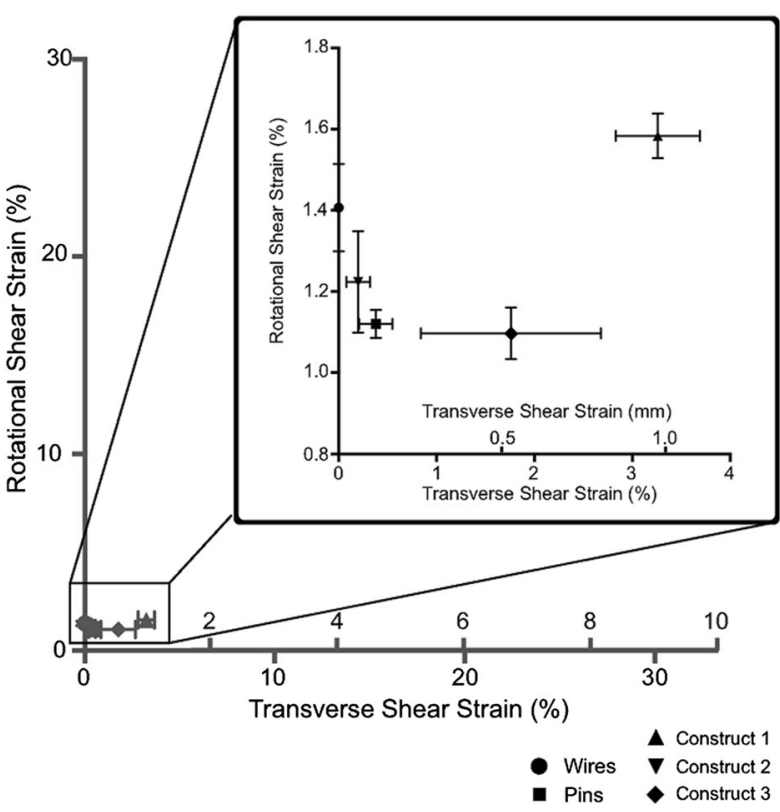

Fig. 5 Maximum rotational and transverse shear strains observed under 5-Nm torsional load are shown.

the wire frames, producing $1.1 \%$ rotational shear strain (mean difference, $0.3 \%, 95 \% \mathrm{CI}, 0.1 \%-0.5 \%, \mathrm{p}=0.011$ ), but with increased transverse shear of $1.8 \%$ (mean difference, $1.8 \%, 95 \% \mathrm{CI}, 0.5 \%-3.0 \%, \mathrm{p}=0.006$ ) By contrast, hybrid construct 2 , also with one half-pin and one wire per ring, but orientated perpendicularly on adjacent rings, showed no difference in rigidity from the all wire-frames, with $1.2 \%$ rotational shear (mean difference, $0.2 \%, 95 \%$ $\mathrm{CI}, 0.0 \%-0.4 \%, \mathrm{p}=0.107$ ), nor any difference in translational shear, at $0.2 \%$ (mean difference, $-0.2 \%, 95 \% \mathrm{CI}$, $-1.4 \%$ to $1.0 \%, p=0.982$ ). Finally, hybrid construct 1 , with only one half-pin per bone segment, although showing no difference in rigidity to the wire frames, with $1.6 \%$ rotational shear (mean difference, $-0.2 \%, 95 \% \mathrm{CI},-0.4 \%$ to $0.1 \%, p=0.166$ ), showed the most marked increase in translational shear strain, of $3.3 \%$ (mean difference, $-3.3 \%, 95 \% \mathrm{CI},-4.5 \%$ to $2.0 \%, \mathrm{p}<0.001)$ (Table 1$)$.

\section{Bending Loading}

The most marked variations in mechanical behavior were observed under bending loads. Bending load of $20 \mathrm{Nm}$ placed on the all-wire frames, with wires in the coronal and sagittal planes, produced a mean of $7.5^{\circ}$ interfragmentary angulation and $21 \%$ transverse shear (Fig. 6). Testing with the wires at $45^{\circ}$ to the coronal and sagittal planes only increased this displacement, producing $8.5^{\circ}$ angulation (mean difference, $1.0,95 \% \mathrm{CI}, 0.7^{\circ}-1.3^{\circ}, \mathrm{p}<0.001$ ) and greater translation at $29 \%$ (mean difference, $8.0^{\circ}, 95 \% \mathrm{CI}$, $\left.4.5^{\circ}-11.4^{\circ}, \mathrm{p}<0.001\right)$. In contrast, the all-pin frames showed $3.4^{\circ}$ interfragmentary angulation with $7 \%$ transverse shear, both lower than seen in the all-wire frames (mean differences, $-4.1^{\circ}$ and $-14.0^{\circ}, 95 \% \mathrm{CI},-4.4^{\circ}$ to $-3.8^{\circ}$ and $-17.5^{\circ}$ to $-10.6^{\circ}$, both $p<0.001$ ). Testing of the hybrid constructs with the half-pins placed in the coronal plane or, in the case of construct 2 , with the pins closest to the fracture in the coronal plane, produced results somewhere between the two, with $4.6^{\circ}, 5.1^{\circ}$, and $4.6^{\circ}$ angular displacement seen in constructs 1,2 , and 3 (vs allwire: mean differences, $-2.9^{\circ},-2.4^{\circ}$, and $-2.9^{\circ}, 95 \% \mathrm{CI}$, $-3.1^{\circ}$ to $-2.5^{\circ},-2.7^{\circ}$ to $-2.1^{\circ}$, and $-3.2^{\circ}$ to $2.6^{\circ}$, all $\mathrm{p}<$ 0.001 ), together with $20 \%, 20 \%$, and $16 \%$ transverse shear (vs all-wire: mean differences, $-1.2 \%,-1.5 \%$, and $-5.6 \%, 95 \% \mathrm{CI},-4.7 \%$ to $2.2 \%,-5.0 \%$ to $1.9 \%$, and $-9.0 \%$ to $-2.2 \%, \mathrm{p}=0.934, \mathrm{p}=0.819$, and $\mathrm{p}<0.001$ ), 


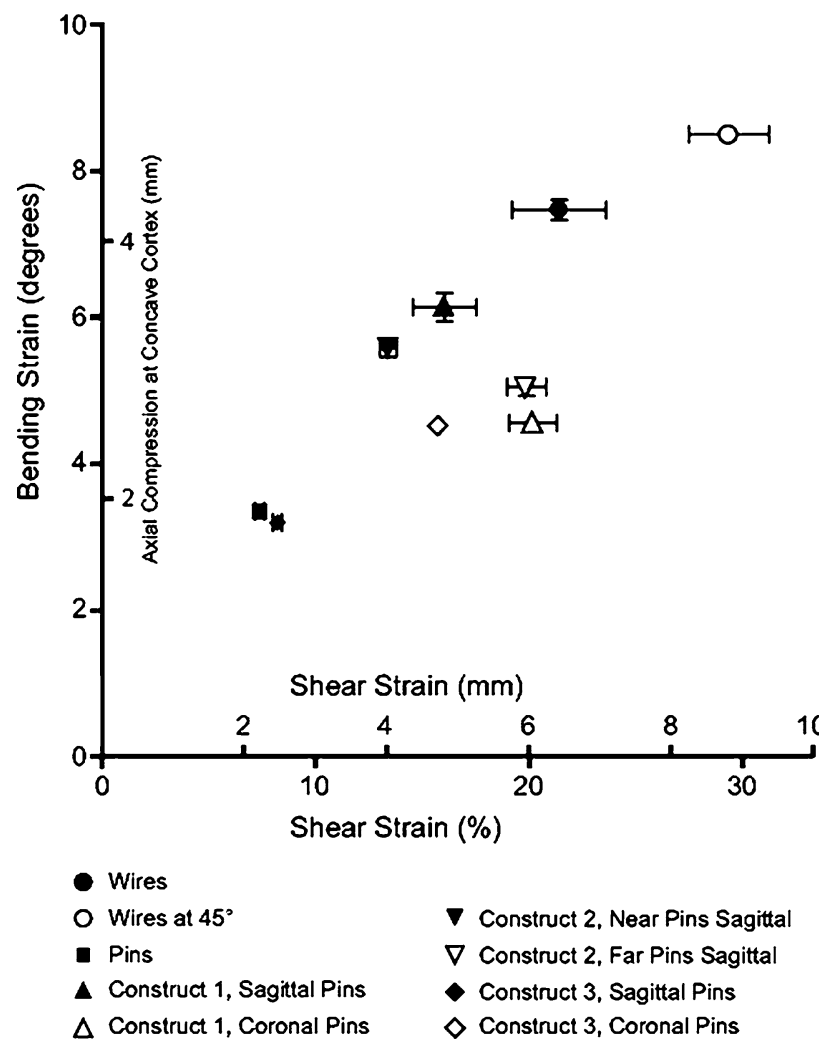

Fig. 6 The maximum bending and shear strains observed under 20$\mathrm{Nm}$ bending load are shown.

respectively. In contrast, placing the half-pins in the sagittal plane (parallel to the plane of applied bending load) reduced transverse shear for all three constructs (vs allwire: $16 \%, 13 \%, 8 \%$; mean differences, $-5.4 \%,-8.0 \%$, $-13.2 \%$; $95 \% \mathrm{CI},-8.8 \%$ to $-1.9 \%,-11.5 \%$ to $-4.6 \%$, $-16.6 \%$ to $-9.7 \% ; \mathrm{p}=0.01, \mathrm{p}<0.001, \mathrm{p}<0.001)$ to levels lower than in the all-wire frames, but most markedly so in construct 3 where transverse shear was reduced to $8 \%$ (mean difference, $-13.2 \%, 95 \% \mathrm{CI},-16.6 \%$ to $9.7 \%, \mathrm{p}<$ 0.001) (Table 1).

\section{Discussion}

The use of circular fixators is well established, with widespread anecdotal and clinical reports of positive outcomes in various challenging cases $[10,18]$. As an entirely modular system, good clinical outcomes rely on an appropriate understanding of how best to apply the frame components, tailored to each patient, to produce a construct which will sufficiently control the mechanical environment at the fracture or osteotomy site to allow bone healing [27, 29]. Developments on the original Ilizarov method of fine-wire fixation have introduced elements, such as threaded half-pins, which allow more versatility in frame application and with reduced muscle transfixion. Although purported to improve patient comfort and tolerance, this has raised concerns that, by altering the mechanics of the frame construct through cantilever bending and introducing increased shear, such elements may have a detrimental effect on the biomechanical environment at a fracture or osteotomy site $[4,6,13]$. Our study was designed to investigate levels of interfragmentary strain occurring in a completely unstable experimental fracture or osteotomy model stabilized by various configurations of a circular frame. The key research questions were: what interfragmentary motion occurs in a fine-wire circular frame under physiologic loading conditions and how is this motion affected by substitution of half-pins for fine-wires in various configurations? By consideration of these results along with what is known about fracture healing environments and fixation approaches $[2,8,11,17,19,30,31]$, we sought to formulate some recommendations regarding favorable frame configurations for fracture healing.

This study has limitations reflecting its experimental nature and methodology, which must be taken into consideration when interpreting the results. Attempts were made during design to limit the number of variables between frames to focus on the specific elements under investigation and improve reproducibility between constructs and testing cycles. This, in addition to the absence of surrounding soft tissues, means that this study is not able or intended to replicate the precise movement of a fracture in vivo, but instead allows analysis of the mechanical effect of specific alterations in frame construction under controlled conditions and relevant comparisons drawn. The acrylic pipe synthetic bone model, rather than being anatomically contoured, is symmetric and uniform, allowing reproducible application and loading of bone fixation elements which would be impossible in cadaveric specimens. Its hollow nature allows "bicortical" fixation, replicating stress distributions on wires and half-pins identified in a previous experimental study [3]. The experimental frame constructs, with idealized fine-wire and pin crossing angles, are not usually possible in the clinical setting, and therefore should be taken in the light of previous work investigating the effect of altered crossing angles on frame mechanical behavior [21, 23]. Moreover, use of synthetic acrylic tubes and idealized wire placement, rather than bone-shaped models and anatomic fixation placement, minimized variability resulting from minor differences in wire positioning or plane of loading, allowing greater confidence in the reproducibility of results between testing cycles, and the precision achieved during three loading cycles for each frame configuration.

Additionally, the simplified loading regimens applied here, with axial, bending, and torsional loads applied separately, does not replicate true multidirectional dynamic loading during gait which would be extremely difficult to 
replicate in vitro, but does allow for better comparison of frame constructs under each mode of loading and helps understanding of the strain induced by each axis of load.

Our study is not intended to replicate the in vivo scenario or specifically analyze the performance of each construct in isolation, but to allow comparison of the effect modifying frame configuration has on mechanical behavior and interfragmentary strain.

\section{Axial Loading}

The pattern of observed interfragmentary strain and construct rigidity under axial loading in an all fine-wire frame correlated closely with previously published data; tensioned fine-wires behaved in a "self-stiffening" nonlinear manner with minimal shear strain observed [1, 13, 32]. Likewise, substitution of half-pins for fine-wires under axial load also produced results in keeping with those described by Gessmann et al. [13], with reduced axial interfragmentary strain and increased shear strain generated by cantilever bending [32]. Despite this increase in axial stiffness, the half-pin construct still generated $4 \mathrm{~mm}$ of mean interfragmentary compression, and with only $1.9 \%$ shear, falling well within the greater than $0.5 \mathrm{~mm}$ axial strain and up to $25 \%$ shear strain reported to induce good bone healing $[2,8,12,19]$. Observed axial interfragmentary strains in the hybrid constructs were not different from those in the all fine-wire construct; however, transverse plane shear strain, similarly to the half-pin construct, was greater, likely reflecting a degree of cantilever bend occurring in the system. The magnitude of this strain in all cases was at levels that appear unlikely to be of clinical importance.

\section{Axial Torsion}

Torsional loading in fine-wire frames produced little interfragmentary transverse plane rotational shear, which was reduced further by the introduction of half-pins. Halfpins, however, did produce increased levels of translational interfragmentary shear strain, particularly with use of a single pin in each bone segment (construct 1), albeit at levels below those likely to be detrimental to bone healing. We found no published studies investigating the behavior of ring fixators under torsional loading against which to compare these findings. Given that clear differences in behavior were seen with substitution of half-pins on axial torsional loading, future studies would benefit from investigating this effect further in a more clinical construct or anatomically correct model.
Bending Loading

Few comparative data exist regarding the behavior of fractures treated with circular frames under bending loads; the only identified comparable work [32] showed little shear strain or angular deformation on loading of a fine-wire frame and a hybrid device similar to construct 3 in the current study. This is in contrast to the high levels of shear strain we observed under physiologic bending loads, a difference which may be attributable to numerous factors: Yang et al. [32] applied four-point bending, centered at the fracture site, producing symmetric deformation and potentially less interfragmentary shear than the more physiologic cantilever loading we used. Furthermore lower forces were applied at $10 \mathrm{Nm}$ torque and a solid synthetic bone analog was used with larger wire contact than cannulated pipe. Finally, the frames we tested were constructed with a larger interfragmentary distance and greater distance between interfragmentary rings than those of Yang et al. [32], both factors intended to emphasize any observed shear strain for comparative analysis. The mechanism of the large interfragmentary shear strains observed in the current study was attributable to a stick-shift mechanism of movement of the bone model along the tension finewires. Even with reportedly ideal $90^{\circ}$ wire crossing angles, flexion of the perpendicular wire allowed displacement of the bone model along the wire parallel to the plane of loading. The addition of half-pins in the plane of bending loading resulted in increased construct rigidity and reduced transverse shear, in keeping with similar findings and conclusions by Yang et al. [32]. This aspect of frame biomechanics warrants further investigation in future studies and particularly in more directly clinically relevant constructs. Although not universally used by frame surgeons, the effect of olive wires in resisting the observed slippage of the bone on finewires would be of particular interest.

\section{Clinical Relevance}

In relating these results to real-world patients, it is important to reflect on not only the existing body of biomechanical evidence, but also the long and well-documented history of successful treatment of a wide variety of fractures and deformities using the Ilizarov method and fine-wire fixators $[10,15,18]$. On this basis, it seems fair to assume that properly applied fine-wire frames produce an environment at a fracture site compatible with bone healing, an assumption largely supported by the results we discussed. The high levels of shear strain seen in finewire frames under bending loads alone fall outside what 
might be considered conditions necessary for bone healing $[2,7,8,12]$. The current study does not aim to simulate an exact clinical scenario, but to allow comparison between constructs, and so these high levels of shear likely represent an experimentally exaggerated magnitude of behavior, attributable to the factors discussed previously, rather than a true in vivo picture. With this caveat however, the comparative findings of this study in the relative effect of substituting fine-wires for half-pins, corroborated by the limited evidence, may be translated to the clinical setting, as well as providing a basis for further research in this area.

Overall, although many of the findings of our study are concordant with those published previously, numerous previously undescribed mechanical behaviors were observed [1, 13, 32]. We did not see the purported clinically significant increase in shear strain, or reduction in axial micromotion, on loading of frames incorporating half-pins. Under simulated physiologic levels of applied axial and torsional load, use of half-pins was seen to produce a more rigid construct, and with a small increase in translational shear at the fracture site, however the clinical importance of these changes in axial and shear strain is doubtful given that magnitudes still fall within levels supported by current evidence as promoting bone healing $[2,8,25]$. If single half-pins are used in a segment however, they appear to act as pivot points; this induces greater levels of rotational shear at the fracture gap and probably should be avoided if possible. Under physiologic bending loads, high levels of shear strain were observed in fine-wire frames, which (although these are unlikely to be representative of true in-vivo levels of shear) illustrates the potential for construct instability during weightbearing. This may be a particular concern in cases of gross fracture comminution, degloved open injuries, or bone transport where lack of bone apposition, support, and wide ring spacing further reduces fracture stability. It is with these scenarios that the findings of our study show that symmetrically placed sagittal near and far half-pins, on rings on either side of the fracture, effectively increase construct stiffness and reduce shear strain associated with bending loads on heel strike during gait beyond that seen with smooth tensioned fine-wire frames [7, 8, 31]. Given the potential advantages in terms of reduced soft tissue transfixion and patient comfort, these findings may allow surgeons more confidence with the use of half-pins under such circumstances although these results need to be corroborated in a clinical model.

Acknowledgments We thank Smith \& Nephew Advanced Surgical Devices (Huntingdon, UK), and Guy Crosby in particular, for donation of the circular frame materials for testing.

\section{References}

1. Antoci V, Voor MJ, Antoci V Jr, Roberts CS. Biomechanics of olive wire positioning and tensioning characteristics. J Pediatr Orthop. 2005;25:798-803.

2. Bishop NE, van Rhijn M, Tami I, Corveleijn R, Schneider E, Ito K. Shear does not necessarily inhibit bone healing. Clin Orthop Relat Res. 2006;443:307-314.

3. Board TN, Yang L, Saleh M. Why fine-wire fixators work: an analysis of pressure distribution at the wire-bone interface. $J$ Biomech. 2007;40:20-25.

4. Calhoun JH, Li F, Bauford WL, Lehman T, Ledbetter BR, Lowery R. Rigidity of half-pins for the Ilizarov external fixator. Bull Hosp Jt Dis. 1992;52:21-26.

5. Calhoun JH, Li F, Ledbetter BR, Gill CA. Biomechanics of the Ilizarov fixator for fracture fixation. Clin Orthop Relat Res. 1992;280:15-22.

6. Catagni M. Atlas for the Insertion of Transosseous Wires and HalfPins. Ilizarov Method. In: Bianchi-Maiocchi A, ed. Milan, Italy: Medi Surgical Video; 2003. Available at: http://osteosyntese.dk/ 3033/Smith-Nephew-Pin-atlas.pdf. Accessed November 18, 2015.

7. Duda GN, Sollmann M, Sporrer S, Hoffmann JE, Kassi JP, Khodadadyan C, Raschke M. Interfragmentary motion in tibial osteotomies stabilized with ring fixators. Clin Orthop Relat Res. 2002;396:163-172.

8. Epari DR, Duda GN, Thompson MS. Mechanobiology of bone healing and regeneration: in vivo models. Proc Inst Mech Eng H. 2010;224:1543-1553.

9. Fleming B, Paley D, Kristiansen T, Pope M. A biomechanical analysis of the Ilizarov external fixator. Clin Orthop Relat Res. 1989;241:95-105.

10. Foster PA, Barton SB, Jones SC, Morrison RJ, Britten S. The treatment of complex tibial shaft fractures by the Ilizarov method. J Bone Joint Surg Br. 2012;94:1678-1683.

11. Gardner MJ, Putnam SM, Wong A, Streubel PN, Kotiya A, Silva MJ. Differential fracture healing resulting from fixation stiffness variability: a mouse model. J Orthop Sci. 2011;16:298-303.

12. Gardner TN, Hardy J, Evans M, Kenwright J. Temporal changes in dynamic inter fragmentary motion and callus formation in fractures. J Biomech. 1997;30:315-321.

13. Gessmann J, Citak M, Jettkant B, Schildhauer TA, Seybold D. The influence of a weight-bearing platform on the mechanical behavior of two Ilizarov ring fixators: tensioned wires vs. halfpins. J Orthop Surg Res. 2011;6:61.

14. Giannoudis PV, Einhorn TA, Marsh D. Fracture healing: the diamond concept. Injury. 2007;38(suppl 4):S3-6.

15. Giotakis N, Panchani SK, Narayan B, Larkin JJ, Al Maskari S, Nayagam S. Segmental fractures of the tibia treated by circular external fixation. J Bone Joint Surg Br. 2010;92:687-692.

16. Goodship AE, Kenwright J. The influence of induced micromovement upon the healing of experimental tibial fractures. $J$ Bone Joint Surg Br. 1985;67:650-655.

17. Goodship AE, Watkins PE, Rigby HS, Kenwright J. The role of fixator frame stiffness in the control of fracture healing: an experimental study. J Biomech. 1993;26:1027-1035.

18. Henderson DJ, Barron E, Hadland Y, Sharma HK. Functional outcomes after tibial shaft fractures treated using the Taylor spatial frame. J Orthop Trauma. 2015;29:e54-59.

19. Kenwright J, Goodship AE. Controlled mechanical stimulation in the treatment of tibial fractures. Clin Orthop Relat Res. 1989;241:36-47.

20. Kummer FJ. Biomechanics of the Ilizarov external fixator. Clin Orthop Relat Res. 1992;280:11-14.

21. Lenarz C, Bledsoe G, Watson JT. Circular external fixation frames with divergent half pins: a pilot biomechanical study. Clin Orthop Relat Res. 2008;466:2933-2939. 
22. Lewis DD, Bronson DG, Cross AR, Welch RD, Kubilis PS. Axial characteristics of circular external skeletal fixator single ring constructs. Vet Surg. 2001;30:386-394.

23. Orbay GL, Frankel VH, Kummer FJ. The effect of wire configuration on the stability of the Ilizarov external fixator. Clin Orthop Relat Res. 1992;279:299-302.

24. Paley D, Fleming B, Catagni M, Kristiansen T, Pope M. Mechanical evaluation of external fixators used in limb lengthening. Clin Orthop Relat Res. 1990;250:50-57.

25. Park SH, O'Connor K, McKellop H, Sarmiento A. The influence of active shear or compressive motion on fracture-healing. $J$ Bone Joint Surg Am. 1998;80:868-878.

26. Pugh KJ, Wolinsky PR, Pienkowski D, Banit D, Dawson JM. Comparative biomechanics of hybrid external fixation. J Orthop Trauma. 1999;13:418-425.

27. Sarpel Y, Gulsen M, Togrul E, Capa M, Herdem M. Comparison of mechanical performance among different frame configurations of the Ilizarov external fixator: experimental study. J Trauma. 2005;58:546-552.

28. Seide K, Weinrich N, Wenzl ME, Wolter D, Jurgens C. Threedimensional load measurements in an external fixator. J Biomech. 2004;37:1361-1369.

29. Spiegelberg B, Parratt T, Dheerendra SK, Khan WS, Jennings R, Marsh DR. Ilizarov principles of deformity correction. Ann $R$ Coll Surg Engl. 2010;92:101-105.

30. Steck R, Ueno M, Gregory L, Rijken N, Wullschleger ME, Itoman M, Schuetz MA. Influence of internal fixator flexibility on murine fracture healing as characterized by mechanical testing and microCT imaging. J Orthop Res. 2011;29:1245-1250.

31. Ulstrup AK. Biomechanical concepts of fracture healing in weight-bearing long bones. Acta Orthop Belg. 2008;74:291-302.

32. Yang L, Nayagam S, Saleh M. Stiffness characteristics and interfragmentary displacements with different hybrid external fixators. Clin Biomech (Bristol, Avon). 2003;18:166-172. 